\title{
TEXTOS SILENCIADOS E TEXTOS TRADUZIDOS: OS EXÍLIOS DE HILDA SIRI DA LITERATURA BRASILEIRA DE EXPRESSÃO ALEMÃ
}

Celeste Ribeiro de Sousa ${ }^{1}$

${ }^{1}$ Universidade de São Paulo, São Paulo, São Paulo, Brasil

\begin{abstract}
Resumo: A palavra exílio, no âmbito da literatura, conduz de imediato a imaginação para o período nazista. No entanto, houve exílios anteriores e posteriores. Igualmente, quando se ouve a palavra, o horizonte da explícita perseguição política se impõe. A pergunta que se faz é se não haveria outras causas, outras circunstâncias para o ser/sentir-se exilado? Se o conceito não atravessaria as fronteiras da e(i)migração? Se, por exemplo, os imigrantes de língua alemã no Brasil (e descendentes) e sua produção literária silenciada não poderiam testemunhar esse modo de estar no mundo? O projeto "Literatura brasileira de expressão alemã" vem se empenhando em organizar esses textos e traduzi-los para o português para que pesquisas possam germinar sobre o assunto. Hilda Siri é um exemplo.
\end{abstract}

Palavras-chave: Brasil Alemão; Literatura de Imigração; Literatura de Minorias

\section{SILENCED TEXTS AND TRANSLATED TEXTS: THE EXILES OF HILDA SIRI OF THE BRAZILIAN LITERATURE WRITTEN IN GERMAN}

\begin{abstract}
The word exile, in the context of literature, immediately leads the imagination to the nazi period. However, there were previous and subsequent exiles. Equally, when the word is heard, the horizon of explicit political persecution arises. The question is whether there would be other causes, other circumstances to be/feel exiled? If the concept would not cross the borders of e(i)mmigration? If, for example, Germanspeaking immigrants in Brazil (and descendants) and their silenced literary production could not witness this way of being in the world? The project
\end{abstract}




\begin{abstract}
"Brazilian Literature written in German" has been striving to organize these texts and translating them into the Portuguese so that research can germinate on the subject. Hilda Siri is an example.
\end{abstract}

Key Words: German Brazil; Immigration Literature; Minority Literature

\title{
1. Exílio
}

A história não é uma narrativa única, mas milhares de narrativas alternativas." (Harari, 184).

Sempre que a palavra "exílio" se faz ouvir, nossos pensamentos rumam em direção aos perseguidos políticos e, em seguida, em direção ao nazismo. Há muitos intelectuais envolvidos nesse tipo de exílio, sendo eles capazes de refletir e escrever sobre esses fenômenos humanos extremos e publicar seus testemunhos, compartilhando-os, na medida do possível, com outros.

Porém, antes desse tempo de triste memória, outros houve que também obrigaram muita gente a se exilar por motivos políticos, como por exemplo, na literatura de língua alemã, Heinrich Heine (1831) e Georg Büchner (1835), refugiados na vizinha França. E para não esquecermos as mulheres, podemos olhar para a francesa Madame de Staël, percorrendo a Alemanha, fugindo de Napoleão, já em 1803.

A palavra "exílio" parece estar sempre atrelada a perseguições políticas. É para lá que Brecht nos leva com o poema: “Über die Bezeichnung Emigranten" publicado em 1937, quando ele já estava exilado na Dinamarca, um poema publicado na revista Die neue Weltbühne, uma revista à época igualmente no exílio em Praga.

Leiamos o que Brecht diz no poema a seguir. Talvez porque também não me sinta definida pelos sememas "Emigranten - emigrantes", "Auswanderer - retirantes, gente que muda de país", "Vertriebene - expulsos", "Verbannte - expatriados, banidos", presentes no poema e nas traduções já feitas por Tercio Redondo e André Vallias, fiz minha própria por conta e risco, continuando, todavia, a me sentir desconfortável. 


\section{Sobre a denominação emigrantes}

Sempre achei falso o nome que nos deram:

Emigrantes.

Isso quer dizer: os que vão para fora. Mas nós

Não fomos para fora de livre vontade

Escolhendo uma outra terra. Também não fomos

Para essa terra, para lá ficar, quem sabe para sempre;

Nós fugimos. Desterrados é o que somos, banidos.

E essa terra não será lar, mas um exílio que nos

Acolheu.

Inquietos ficamos, o mais perto possível das fronteiras

À espera do dia do regresso, cada mínima alteração

Além da divisa observando, a todos que chegam

perguntando ansiosos, nada esquecendo e de nada desistindo

E também nada perdoando do que aconteceu, nada perdoando.

Ah! a calma do mar estreito não nos engana! Nós ouvimos os

Gritos

\section{Über die Bezeichnung Emigranten}

Immer fand ich den Namen falsch, den man uns gab:

Emigranten.

Das heißt doch Auswandrer. Aber wir

Wanderten doch nicht aus, nach freiem Entschluss

Wählend ein andres Land. Wanderten wir doch auch nicht

Ein in ein Land, dort zu bleiben, womöglich für immer

Sondern wir flohen. Vertriebene sind wir, Verbannte.

Und kein Heim, ein Exil soll das Land sein, das uns da aufnahm

Unruhig sitzen wir so, möglichst nahe den Grenzen

Wartend des Tags der Rückkehr, jede kleinste Veränderung

Jenseits der Grenze beobachtend, jeden Ankömmling

Eifrig befragend, nichts vergessend und nichts aufgebend Und auch verzeihend nichts, was geschah, nichts verzeihend. Ach, die Stille der Sunde täuscht uns nicht! Wir hören die

Schreie 
Lá dos campos bem aqui. Nós mesmos somos

como que rumores de crimes que de lá escaparam

Através das fronteiras. Cada um de nós, Que, de sapatos rotos, passa pelo meio das massas,

Testemunha a vergonha que agora mancha nossa terra.

Mas nenhum de nós

Ficará aqui. A última palavra Ainda não foi dita.
Aus ihren Lagern bis hierher. Sind wir doch selber

Fast wie Gerüchte von Untaten, die da entkamen

Über die Grenzen. Jeder von uns

Der mit zerrissenen Schuhn durch die Menge geht

Zeugt von der Schande, die jetzt unser Land befleckt.

Aber keiner von uns

Wird hier bleiben. Das letzte Wort

Ist noch nicht gesprochen. (Brecht 718).

Para Brecht, a palavra “emigrantes” não traduz as circunstâncias precisas dos perseguidos do Nazismo: judeus, comunistas, artistas, minorias de qualquer tipo. Aqueles que não conseguiram fugir, gritam dos campos de concentração e seus gritos chegam a todos os lugares por mais longínquos que estejam. Os que conseguiram fugir, como o próprio Brecht, por exemplo, ou Döblin, ou os irmãos Thomas e Heinrich Mann, Anna Seghers, Else Lasker-Schüler, Nelly Sachs, Paula Ludwig, Rose Ausländer, Hilde Domin, seriam os exilados que aguardam o regresso para dizer a última palavra. De fato, um dos primeiros exílios de que há memória é um exílio político, é o exílio do povo judeu na Babilônia durante 50 anos, quando foi submetido por Nabucodonosor e levado escravo cerca de 600 anos antes de Cristo.

Mas, durante o Nazismo, no campo da literatura, além das obras tecidas segundo as regras do regime, a chamada "Blut-und-Boden-Literatur" ou "Blubo-Literatur" e os livros publicados no exílio estrangeiro, a "Exilliteratur", há um outro tipo de exílio, o chamado exílio interior, em alemão denominado como "innere Emigration", que leva os escritores a procurarem refúgio no seu íntimo porque não aceitam as ideias nazistas e, por questões familiares ou outras, também não querem ou não podem sair de seu país. Seu 
silenciamento temporário a respeito da situação política, sua recusa ao engajamento, é igualmente visto como um tipo de resistência. Vários autores se encaixam aqui. Só para ficar nas mulheres, temos Ricarda Huch, Gertrud von Le Fort, Marie Luise Kaschnitz (que era amiga de Adorno e esteve inclusive no Brasil em 1962 e escreveu/traduziu o país). E há as controvérsias em torno de Gottfried Benn e Ernst Jünger, que foram e não foram nazistas.

O professor francês de literatura comparada Alexis Nouss, no livro La condition de l'éxile, de 2015, oferece uma extensa análise semântica para o complexo lexical em torno deste assunto. Mas, se levarmos em consideração o campo semântico do vocábulo ou do semema "exílio", no Dicionário Houaiss, já lá encontraremos cinco significados ou semas, todos sem menção ao fator político, religioso ou étnico. Exílio pode ser:

1. expatriação forçada ou por livre escolha; degredo.

2. lugar em que vive o exilado.

3. lugar longínquo, afastado, remoto.

4. isolamento do convívio social; solidão.

O significado invocado por Brecht é o da "expatriação forçada". O significado inerente à "innere Emigration" é contemplado pelo "isolamento do convívio social”. Mas ainda há outros tipos de exílio que se acham no campo semântico geral da emigração. De fato, no mesmo dicionário, o semema "emigração" aparece com dois semas que enfatizam, sobretudo, o movimento:

1. saída espontânea de um país, definitiva ou não.

2. movimentação de uma para outra região dentro de um mesmo país.

Poderíamos dizer que o exílio por livre escolha é uma modalidade da emigração. Mas o uso corrente das palavras "exílio" e 
“emigração" com fronteiras frequentemente atravessadas deixa as discussões muito confusas. $\mathrm{O}$ deixar a pátria ${ }^{1}$ para trás, quaisquer que sejam as circunstâncias, de qualquer forma, deixa marcas indeléveis, que podem emergir na vida do exilado ou emigrado com maior ou menor intensidade.

Dizem os psiquiatras Alexei Conte Indursky e Luiz Eduardo Prado de Oliveira no artigo "A melancolização do exílio", de 2016, que,

ao contrário do que secularmente se convencionou, o refúgio é por excelência um objeto ambivalente [...]. O traço comum desse público [os exilados] é o fato de terem vivido um estado de exceção 'provisoriamente permanente', no qual a vida é reduzida ao mero valor do corpo ([citando Ce qui reste d'Auschwitz, de] Agamben, 2003) e a busca por sobrevivência se impõe ao psiquismo como lógica reinante. Se as experiências de separação e de perdas remetem à finitude, ao irrepresentável da morte e todo seu corolário de angústias, quando vividas em exílio elas se intensificam sobremaneira. (Indursky and Oliveira 243).

Afinal, como deveríamos designar as pessoas que, diante da miséria econômica, sem disporem de ajuda de qualquer tipo, são obrigadas a deixar seus países para garantirem o alimento diário em outros lugares? Seriam elas simples emigrantes que fizeram uma escolha livre? Não seriam elas também pessoas expatriadas, de alguma forma, forçadas a viver no estrangeiro?

Dentre as causas mais frequentes para a emigração forçada e, portanto, para o exílio, também estão as econômicas, ontem e hoje, frequentemente acopladas a injunções de ordem política! Trata-se,

${ }^{1}$ Ver a análise do semema pátria em “A destruição da sacrossanta”, de Manuel Domingos Neto. Disponível em < https://aterraeredonda.com.br/a-destruicao-daacrossanta/?utm_source $=$ rss\&utm_medium $=$ rss\&utm_campaign $=$ a-destruicaoda-sacrossanta\&ütm_term $=2020-0 \overline{9}-01>$. 
no fundo, de perseguições indiretas cheias de matizes, a sufocar a autorrealização plena do indivíduo.

No Brasil imperial, por exemplo, várias motivações estão por trás da imigração ou exílio: motivações políticas (era preciso povoar as imensidões do país, formar um exército disciplinado e treinado para assegurar suas fronteiras, e esta necessidade brasileira casava-se à perfeição com a miséria econômica grassante nos países de língua alemã e outros, causada por várias guerras, com propriedades agrícolas devastadas, camponeses esfomeados e soldados sem trabalho, como tão bem retrata Kasimir Edschmid em Deutsches Schicksal, embora em outra época); por trás da imigração ou do exílio dos estrangeiros no Brasil imperial, estavam também as motivações eugenistas (a elite brasileira queria branquear a população) e por trás da imigração ou do exílio dos estrangeiros no Brasil havia ainda as motivações econômicas locais (era preciso angariar para o Brasil mão de obra rural para fazer frente à produção agrícola do país, a braços com o fracasso da escravização dos índios e, depois, com a insuficiência da mão de obra negra escrava, para um país de dimensões continentais e também com a pressão internacional pela abolição da escravatura). A propaganda das terras paradisíacas brasileiras, feita em terras de língua alemã, para atrair não só camponeses empobrecidos e levados à miséria ao tempo das invasões napoleônicas e das revoluções liberais de 1848, e até indivíduos remediados, é relatada, por exemplo, pelo Pastor prussiano Otto Grellert, falecido em 1993 no Brasil, numa narrativa intitulada $A$ cada um seu paraíso, já disponível em alemão e em português no e-book Otto Grellert (1908-1993): vida e obra. Diz o narrador:

Alemão! Por que você ainda trabalha como peão para
patrões estranhos? Por que você continua passando fome
num pedacinho de terra? Faça as malas e vá para o Bra-
sil! O país mais rico do mundo, com as suas intermináveis
matas virgens, espera por você. Lá, também você pode
tornar-se senhor de sua própria terra. O melhor solo do
Brasil está sendo justamente agora distribuído e liquidado. 
O lugar, onde a mais moderna cidade deve ser construída com igrejas, escolas, hospitais, bancos e lojas, já está demarcado. O projeto já foi totalmente concluído. Avenidas largas de primeira classe logo serão construídas, e até mesmo a construção de ferrovias está prevista para breve. Em cada colônia de terra há tanta madeira que, só com ela, pode-se pagar o preço estipulado. Operários! Pequenos agricultores! Corram! Garantam a vocês e aos seus filhos o futuro! Garantam para vocês o melhor chão do Brasil! (Trad. Gregory 1-2).

\section{Duplo exílio}

Foi em condições semelhantes, com muitos percalços, que os antepassados da escritora Hilda Siri (pseudônimo de Hilda Iris Zwanziger) chegaram ao Brasil. Aliás, a saga de seus antepassados da Europa até o Brasil é reconstruída/traduzida pela escritora numa narrativa memorialista, montada em cima de vários flashbacks, publicada em 1952. O baú carregado pela família na viagem, com que a narradora estabelece um diálogo, na verdade, um longo monólogo, é real e encontra-se exposto no museu da cidade de Ijuí. Esta narrativa intitula-se $O$ velho baú e também já pode ser encontrada em alemão e em português no e-book Hilda Siri (1918-2007): vida e obra.

Figura 1: Hilda Siri (1918-2007)

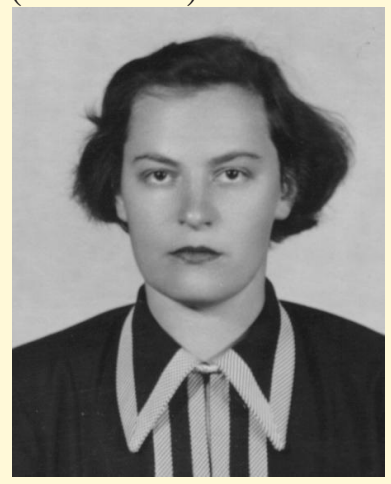

Cad. Trad., Florianópolis, v. 41, no 3 p. 298-318, set-dez, 2021. 
Hilda Siri, falecida em 2007, já é brasileira, descendente de imigrantes alemães, mas é como se não fosse, pois embora tenha nascido e crescido em Ijuí (Rio Grande do Sul), casa com um alemão e vive dentro de uma comunidade absolutamente alemã, na língua, nos costumes, na educação. Os livros vêm da Alemanha via Buchgemeinschft, as revistas são enviadas por parentes; as notícias chegam da Alemanha pela emissora deutsche Rundfunksendung. Hilda Siri, de educação esmerada, só vem a tomar consciência de que o Brasil em que vive não é alemão, quando Getúlio Vargas, em 1939, proíbe o uso de línguas estrangeiras nas escolas e, depois, em público. Hilda Siri tem então 21 anos! Diz ela numa pequena Autobiografia do espólio: "Os antes alemães, italianos, poloneses, letônios, russos, etc. tiveram que passar a ser brasileiros do dia para noite!" 2 . E, mais adiante, fala de tempos em tudo parecidos com exílio: "Quando a Segunda Guerra Mundial acabou, sobrevieram anos de que não gosto de falar. E isso também não leva a lugar algum. Pois quem não experimentou a situação, não entenderá". ${ }^{3}$ Diante de tais palavras, não podemos deixar de lembrar e parar para refletir, resguardados os devidos contextos e distâncias, sobre a coincidência com a frase de Elie Wiesel (1975), citada por Agamben (1998) em $O$ que resta de Auschwitz. Diz ele: "os que não viveram aquela experiência nunca saberão o que ela foi; os que a viveram nunca o dirão; realmente, não, até o fundo [...]." (Wiesel apud Agamben 42). Quando Hilda Siri visitou a Alemanha com uma bolsa do Goethe Institut de Porto Alegre e foi a Nürnberg, nada a prendeu lá. É assim que ela registra sua experiência numa narrativa intitulada "Die Parade", que traduzo a seguir.

2 "Aus den ehemaligen Deutschen, Italienern, Polen, Letten, Russen, u.s.w. sollten über Nacht Brasilianer werden." (Documento do espólio da escritora, datado de 2000, intitulado Autobiografie, gentilmente cedido por seu filho Marcus Zwanziger).

3 “Als der zweite Weltkrieg zu Ende war, kamen Jahre von denen ich ungern spreche. Und es hat auch keinen Zweck. Denn wer so was nicht durchgemacht hat, versteht es nicht." Id. ibib. 


\section{O desfile}

Encontrava-me eu num bonde, passeando por Nürnberg. Já não era mais uma jovem e usufruía uma bolsa do Instituto Goethe na Alemanha. No domingo, saindo de Munique, tínhamos feito uma excursão a essa cidade tão antiga, tínhamos visitado a catedral, o castelo, onde, na Idade Média, a dieta do império se reunia, apreciamos a casa de Dürer, tudo explicado e esclarecido por um professor de história da arte, passeamos pela praça com a bela fonte e caminhamos pelo milenar muro da cidade por um tempo.

Agora, eu desfrutava de um período livre das 4 às 8 , depois, deveria encontrar-me com o grupo num restaurante, onde jantaríamos, para em seguida iniciarmos o regresso.

Eu estava cansada, mas ainda não tinha vista uma coisa, que, realmente, precisa ser vista, quando se vem a Nürnberg uma vez na vida: o Campo de Marte.

Encontrava-me no assento perto do condutor. O bonde tinha pouca gente. Foi ao condutor que dirigi a palavra: 'Será que estou no bonde certo para o Campo de Marte?' 'Sim. O que vai fazer no Campo de Marte?' perguntou ele, divertido. 'Não há nada para ver lá.' 'Mas, já houve', retruquei no mesmo tom. 'Por favor, avise-me quando eu tiver que descer.' 'Bom, então, vai ter de seguir comigo até a estação final e, depois, andar a pé um bom bocado. Tem certeza que quer ir até o campo de Marte? Lá, não há nada mesmo para se ver.' 'Para ver ou não', eu ri atrevida, 'eu quero ter estado lá.'

Gostei da conversa. De repente, ele olhou para mim curioso e baixando a voz: 'A senhora também participou daquilo?' Tive que rir. 'Primeiro, nessa época, eu ainda era quase uma criança e, segundo, eu sou brasileira.'

Os outros passageiros começavam a prestar atenção e escutavam curiosos a conversa. 'Bom. Quando chegar o momento e querendo realmente... Os estrangeiros, às vezes, têm cada ideia estranha.' 'Eu não diria que a Senhora é uma estrangeira,' admirou-se um dos passageiros. 'A Senhora fala alemão como uma alemã.' Expliquei-lhe com brevi- 
dade as minhas circunstâncias: descendente de emigrantes alemães, escola alemã, mais tarde professora de alemão. Um outro quis saber como eram as coisas em Blumenau, ele lera sobre isso nos livros escolares. Quando alcançamos a última parada, eu e o condutor já éramos amigos e os outros passageiros simpáticos conhecidos.

Eu desci. 'Por ali, à direita, e sempre em frente, falou o condutor. Mas a Sra. precisa apressar-se; logo vai escurecer.'

Comecei a andar a passos largos por uma calçada ampla, que pareceria bem comprida. À direita, uma rua de mão dupla, carros para lá e para cá, e do outro lado, blocos de casas, de três a cinco andares, novos, modernos, todos de cores claras diferentes, tudo limpo com planos gramados, árvores e arbustos.

À esquerda, sim, devia ser ali. Uma grande planície gramada, ao fundo, uma construção meio decadente, que se assemelhava em tudo ao coliseu de Roma. Apressei-me. Ali estava o relvado imenso, sem fim. Lá longe, uma espécie de arco do triunfo, meio em ruínas. 'Como na antiga Roma', ouvi a voz de um professor de meus tempos de escola. Então, era aqui que se realizavam os grandes desfiles, que eu vira em ilustrações e em filmes. Era esse o espaço que ouvira os grandes apelos 'ao meu povo', que eu escutara no rádio, na emissora alemã. Era essa a grama que havia sido pisada por oficiais uniformizados, marchando no mesmo ritmo compassado, há uma, não, há quase duas gerações.

Olhei em volta de mim. O sol havia se posto e, no céu avermelhado da tardinha, a argêntea e delgada foice lunar fazia sua entrada.

Eu estava absolutamente sozinha. Sozinha num espaço cultural que definiu o destino da Europa e a vida de milhões de pessoas. Senti calafrios e um medo gelado acelerou meu passo. No coliseu, algumas janelas estavam iluminadas. Havia americanos instalados lá, disseram-me.

O último pedaço do caminho fiz a correr. Quando alcancei o terminal, um bonde já lá estava posicionado. O mesmo motorneiro cumprimentou-me de modo exuberante, como 
se tivesse esperado por mim. Voltei a sentar-me perto dele. 'A Senhora viu tudo o que queria?' 'Acho que sim'. 'Desapontada?' Eu não sabia o que dizer. 'Também viu as colunas de mármore de Carrara, que Mussolini nos ofereceu?' 'A tanto não cheguei.' 'Então, a Sra. precisa voltar mais uma vez a Nürnberg. A Sra. perdeu o que há de mais bonito. De fato, já era muito tarde', disse ele para me confortar. Mais uma vez? Quando é que eu voltarei mais uma vez à Alemanha? Como poderia eu imaginar tudo o que ali acontecera outrora... Os desfiles... Assenti com a cabeça. E, de maneira abrupta, lembrei-me de algo: a 'Stadtplatz', a praça da minha cidadezinha natal.

Eu me vi mocinha durante um passeio. De súbito, dobrando uma esquina, surgiu um pelotão de homens de uniformes marrons, botas pretas, na manga direita a insígnia do partido nacional-socialista NSDAP. Talvez uns vinte homens. Marchavam estrondosamente em passadas uniformes sobre os paralelepípedos da rua. Era um comando resoluto - eles marchavam em ritmo compassado em volta da praça. De novo, um comando. Pararam, passaram à posição de sentido e, então, ouviu-se bem alto e intimidante a canção de Horst Wessel ${ }^{4}$, seguida por um esgoelado 'Heil Hitler'. Eu conhecia todos os que ali cantavam: cidadãos honestos, artesãos, pequenos comerciantes, um de meus professores e o Pastor Missouri.

Poucas pessoas pararam para assistir à parada. Ninguém deu um pio. Não consigo colocar em palavras o que me abalou. Sei apenas de uma coisa: fiquei envergonhada. Sem querer, as lágrimas rolaram-me pelas faces. Será que estava com saudades de casa? Fora de mais para um só dia.

${ }^{4}$ A "Horst Wessel Lied, também conhecida como Die Fahne hoch, era o hino oficial da SA, tornando-se posteriormente o hino do Partido Nacional Socialista (NSDAP), cuja letra foi composta por Horst Wessel, membro do partido em seus primeiros anos. Durante o Terceiro Reich, a Horst Wessel Lied tornou-se um dos hinos oficiais da Alemanha. Após a queda do nazismo, em 1945, a canção foi proibida no país”. Disponível: https://pt. wikipedia.org/wiki/Horst-Wessel-Lied. 
Afinal, qual era o país de Hilda Siri? A Alemanha ou o Brasil? A Alemanha porque tinha sangue alemão? O Brasil porque aqui nascera? Eram os dois e não eram. Ela habitava um espaço e um tempo imaginários entre dois mundos: a Alemanha e o Brasil. A sua vivência de pertencimento estava em suspenso. E isso é um duplo exílio. Na verdade, ela não era uma "teuto-brasileira" com duas identidades justapostas; ela era uma "brasale" ou coisa que o valha, uma nova identidade, sui generis.

Hilda Siri é durante bastante tempo, professora do Goethe Institut em Porto Alegre e, depois, trabalha no jornal Serra-Post e na editora Ulrich Löw em Ijuí. Aqui, como colaboradora e funcionária do jornal Serra-Post, além de traduzir Câmara Cascudo, Coelho Neto, Machado de Assis, Olavo Bilac, Raimundo Correa, Simões Lopes Neto para o alemão, Hilda Siri publica inúmeros poemas, muitas narrativas de cunho memorialista e muitos ensaios no "Cantinho Feminino" (Frauenecke) do jornal, ensaios esses de cunho marcadamente feminimo, tendo inclusive despertado a fúria de um leitor. Dela é também o ensaio intitulado "Letras localistas", já traduzido para o português no seu e-book Hilda Siri (1918-2007): vida e obra, em que afirma haver uma diferença básica entre as narrativas escritas antes dessa ordem do Getúlio e as narrativas escritas depois. Segundo ela, as editoras e mesmo os escritores, que queriam ver suas obras publicadas, passaram a praticar autocensura. Eis aqui uma hipótese valiosa para investigação e demonstração num doutorado, assim como a análise das traduções por ela efetuadas.

Suas poesias abordam temas vários. Abaixo, um trecho, ou melhor, a IV estrofe, de um poema intitulado "Kleinigkeiten" (Insignificâncias), de 2000, em minha tradução livre, um poema com um pé lá e outro cá:

Caros teuto-brasileiros

já lhes passou pela mente a obra de um Wolfgang Goethe brotando no florestal ambiente?
Ihr lieben Bras-Teutonen habt ihr schon überdacht, was wohl ein Wolfgang Goethe im Urwald hätt' vollbracht? 
Quem do gênio falaria

Se em Ijuí nascido teria?
Wer spräche heut' von dem Genie, Wär' er geboren in Ijuí? (Siri 141).

É dela também o seguinte poema, publicado no mesmo ano, sobre a volta para casa, a acenar com sentimentos do exílio em todos os matizes, em minha tradução livre:

\section{Tu podes, sim, retornar}

Tu ainda podes retornar, se quiseres.

A velha casa ainda está cercada de verde;

No pátio, a fonte sussurra a melodia,

Que te acompanhou desde sempre.

As árvores alternam flores, frutos

E seus próprios cheiros doces

Desejam atrair-te para casa.

Se te sentires só no mundo estranho...

Vem pra casa, é só quereres.

Vem pra casa.

Tu continuas a ter um lar.

Quantos, quantos não o têm.

Se neste mundo estás solitário, Isso nunca é estar sozinho.

\section{Du kannst ja heimkehren}

Noch immer kannst du heimkehren, wenn du willst.

Das alte Haus steht immer noch im Grün;

im Hof, der Brunnen rauscht die Melodie, die dich umfing von spät bis früh.

Die Bäume wechseln Blüten, Früchte und ihre eigenen süßen Düfte sie wollen dich nach Hause ziehen. Fühlst du dich in der fremden Welt allein...

Komm heim, wenn du nur willst. Komm heim.

Du hast noch immer eine Heimat. Wie viele, viele haben keine. Bist du auf dieser Welt allein, Bist du doch niemals einsam. 
Que te console a certeza:

A casa paterna te aguarda.

Alegra-te! Ainda podes retornar, caso queiras.

A casa paterna sempre será teu lar.
Eine Gewissheit tröstet dich:

Dein Elternhaus wartet auf dich.

Sei froh! Du kannst noch heimkehren, wenn du willst.

Dein Elternhaus ist immer dein daheim.

Dort spürt ein jeder, was dein Herz bewegt, Und kennt die Welle, die dich hebt und trägt.

Die Seligkeit strömt doppelt dir zurück.

Dort darfst ein Kind du wieder sein. Komm heim! (Siri 106).

Essa situação que aponta para o exílio faz lembrar o ensaio de Edward Said "Reflexões sobre o exílio", quando ele diz:

Ele [o exílio] é uma fratura incurável entre um ser humano e um lugar natal, entre o eu e seu verdadeiro lar: sua tristeza essencial jamais pode ser superada. E, embora seja verdade que a literatura e a história contêm episódios heroicos, românticos, gloriosos e até triunfais da vida de um exilado, eles não são mais do que esforços para superar a dor mutiladora da separação. As realizações do exílio são permanentemente minadas pela perda de algo deixado para trás para sempre. (Said 46).

Tal situação também se faz presente num conto de apenas três páginas, intitulado $A$ vingança da floresta virgem. Um destino de imigrante, também constante em alemão e em português no e-book citado. Neste conto, a história, concisa e concentrada num único 
clímax, é contada numa linguagem sóbria, de significativo poder imagético, no desenrolar de uma única cena, em um só dia, por uma narradora que se pode, em parte, confundir com a autora, que registra suas memórias de outras memórias, e por uma personagem feminina - mãe de família, emigrada recentemente da Alemanha com o marido e onze filhos. A voz masculina inexiste. Apenas uma outra voz é potente e se faz ouvir: a de sua grande inimiga - a floresta virgem brasileira, com quem se confronta. A alemã é uma mulher forte que ombreia com o marido no sustento da família. O confronto com a floresta é seu único modo de sobrevivência. A floresta é o Brasil e o Brasil é a floresta. Uma floresta personificada, vingativa, invadida por forasteiros atrevidos. O preço do embate final entre esta natureza e essa mãe (imigrante) é trágico: a mãe de família sucumbe à derrubada de uma árvore, que sobre ela se abate, matando-a. Mas, nos últimos minutos, esta mãe, um Prometeu de saias, ainda incumbe o filho menor de atear o fogo costumeiro à floresta. Não há trégua no afã de construir um novo mundo. A luta entre natureza e civilização, ou incivilização, persiste para além das tragédias familiares até hoje. Um tema universal de extrema atualidade. A morte é apenas a chegada da paz e do silêncio: uma morte aberta, que tanto pode ser recebida como uma morte católica, protestante ou existencialista. O corpo fatalmente ferido jaz como alegoria do último refúgio do indivíduo desenraizado, alegoria da ruptura imbricada no exílio, alegoria do não pertencimento, da exclusão.

Outras narrativas poderiam aqui ser evocadas para emparelhar com esta, a mostrar o ambíguo exílio dessa gente de língua alemã em terras brasileiras. Gente perdida, isolada em locais estranhos, hostis.

\section{Exílio atávico}

Lembremo-nos que muitos (se não todos) dos que habitam o Brasil ou são imigrantes ou são seus descendentes em escalas geracionais e de estranhamento linguístico variadas. Será que esses 
indivíduos não trazem em seu inconsciente coletivo essa vivência do exílio? Será que não somos todos nós um tanto exilados como quer Julia Kristeva, ela mesma emigrante/exilada búlgara em Paris, quando afirma que somos estrangeiros dentro de nós mesmos (nous tous étrangers à nous-mêmes). No fundo, ser imigrante ou exilado é ter um "Dasein" tensamente acomodado entre dois mundos, um enraizamento desenraizado, é ser a própria alegoria do oxímoro. $\mathrm{E}$, querendo, ir mais fundo no assunto, na desejável/(im)possível conciliação dessa polaridade, poderíamos chegar aos conceitos de "Selbst/Self" e de "individuação" (Individuationsprozess), desenvolvidos pela chamada psicologia profunda de C.G. Jung. O (ego) exilado teria o trabalho extra de integrar harmoniosamente ao eu mais essa experiência de rompimento em vários níveis de dramaticidade e rumar para o ideal - o entendimento ou a conscientização de seu lugar de interação no mundo coletivo, isto é, ser inteiro, indivisível, distinto, empático e não narcísico. Mas em que língua? Em que dialeto? Em que idioleto?

Se naquelas pessoas, que estão explicitamente vivendo em exílio, isto é, de um modo ou de outro, obrigatoriamente no estrangeiro, a tensão entre os dois mundos está clara, é palpável e é compreensível, nos descendentes dos imigrantes/exilados, isso passa a ser encoberto, mas não menos tenso. Projete-se esse raciocínio para um país como o Brasil em que não há só imigração vinda de fora das fronteiras, mas também dentro das próprias fronteiras. E não só ontem como também hoje. O Brasil é um país de imigrantes e de seus descendentes à procura de uma identidade coesa nas muitas diferenças, ainda.

Será que a história da literatura brasileira não deveria contemplar com um capítulo a produção literária desses imigrantes/exilados, eles mesmos também tradutores de tantas obras da literatura brasileira, eles que urdem uma imagem sui generis da realidade do país? Não nos podemos esquecer que um cânone literário é um constructo cultural. Seus limites são, portanto, artificiais e estão sujeitos a mudanças. A isso se refere Wander Melo Miranda no ensaio "Nações literárias", publicado no livro do mesmo nome. 
O projeto "Literatura brasileira de expressão alemã" já disponibiliza online muitas traduções desses textos silenciados com o fito de amenizar o "exílio" linguístico desses autores e proporcionar solo fértil à germinação de mais pesquisas.

\section{Referências}

Agamben, Giorgio. Quel che resta di Auschwitz. L'archivio e il testimone. Torino: Bollati Boringhieri, 1998.

Agamben, Giorgio. O que resta de Auschwitz. O arquivo e a testemunha (Homo Saccer III). Trad. Selvino Assmann. São Paulo: Boitempo, 2008.

Brecht, Bertolt. Gesammelte Werke 9. Gedichte 2. Frankfurt a. M.: Suhrkamp, 1967, p. 718.

Brecht, Bertolt. “Acerca do termo imigrantes”. Trad. Tercio Redondo. Traulito, $\mathrm{n}^{\mathrm{0}} 2$, julho/agosto de (2010): 14.

Brecht, Bertolt. "Sobre a designação de emigrantes". Bertolt Brecht: poesia. André Vallias (Ed.). Trad. André Vallias. São Paulo: Perspectiva, 2019, p. 326.

Edschmid, Kasimir. Deutsches Schicksal. Berlin: Zsolnay, 1932.

Grellert, Otto. "Jedem sein Paradies”. Serra-Post-Kalender. Ijuí: Ulrich Löw, 1954, p. 173-182.

Grellert, Otto. “A cada um seu paraíso”. Otto Grellert (1908-1993): vida e obra. João Alceu Gregory (Ed.). São Paulo: Instituto Martius-Staden, 2012. Disponível em: http://www.martiusstaden.org.br/files/conteudos/0000001-0000500/118/ ce12156180565ff561943fdc9389cd76.pdf. 
Harari, Yuval Noah. Homo Deus. Trad. Paulo Geiger. São Paulo: Companhia das Letras, 2016.

Houaiss, Antônio. Dicionário Houaiss de língua portuguesa. Rio de Janeiro, Objetiva, 2007

Indursky, Alexei Conte; Oliveira, Luiz Eduardo Prado de. "Sobre a melancolização do exílio". Revista Latinoamericana de Psicopatologia Fundamental. 19 (2), jun. (2016): 242-258. Disponível em: https://www.scielo.br/pdf/rlpf/v19n2/14154714-rlpf-19-2-0242.pdf.

Kristeva, Julia. Étrangers à nous mêmes. Paris: Gallimard, 1991.

Kristeva, Julia. Estrangeiros para nós mesmos. Trad. Maria Carlota Carvalho Gomes. Rio de Janeiro: Rocco, 1994.

Miranda, Wander Melo. Nações literárias. São Paulo: Ateliê, 2009.

Neto, Manuel Domingos. “A destruição da sacrossanta”. Disponível em https:// aterraeredonda.com.br/a-destruicao-da-sacrossanta/?utm_source $=$ rss\&utm medium $=$ rss\&utm_campaign $=$ a-destruicao-da-sacrossanta $\& u$ tm_term $=2020$ 09-01.

Nouss, Alexis. La condition de l'éxile. Paris: Editions de La Maison des Sciences de l'Homme, 2015.

Nouss, Alexis. Pensar o exílio e a migração hoje. Trad. Ana Paula Coutinho. Porto: Edições Afrontamento, 2016.

Ribeiro-de-Sousa, Celeste. Hilda Siri (1918-2007): vida e obra. São Paulo: Instituto Martius-Staden, 2008. Disponível em: http://www.martiusstaden.org.br/conteudo/ detalhe/102/hilda-siri-1918-2007.

Said, Edward. Reflexões do exílio e outros ensaios. São Paulo: Companhia das Letras, 2003. 
Siri, Hilda. "Die alte Truhe”. Serra-Post Kalender. Ijuí: Ulrich Löw, 1952, p.8192.

Siri, Hilda. "O velho baú”. Trad. Celeste Ribeiro de Sousa e Maria António Hörster. Hilda Siri (1918-2007): vida e obra. São Paulo: Instituto Martius-Staden, 2008. Disponível em: http://www.martiusstaden.org.br/files/conteudos/00000010000500/102/08395d1b29ae12bca4f21e7f664b4d6f.pdf.

Siri, Hilda. "Die Rache des Urwalds”. Serra-Post Kalender. Ijuí: Ulrich Löw, 1955, p. 107-110.

Siri, Hilda. "A vingança da floresta virgem”. Trad. Maria António Hörster. Hilda Siri (1918-2007): vida e obra. São Paulo: Instituto Martius-Staden, 2008. Disponível em: http://www.martiusstaden.org.br/files/conteudos/00000010000500/102/88dab2b7d02225dbcef769c833a2d409.pdf.

Vergueiro, Paola Vieitas. “Jung, entrelinhas: reflexões sobre os fundamentos da teoria junguiana com base no estudo do tema individuação em Cartas". Psicologia: teoria e prática. V.10. $\mathrm{n}^{0} 1$. jun. 2008: 125-143. Disponível em: http://pepsic. bvsalud.org/pdf/ptp/v10n1/v10n1a10.pdf.

Wiesel, Elie. "For some measure of humility". Sh'ma: a journal of jewish responsibility. 31 oct. (1975): 314.

Zwanziger, Iris. Die alte Truhe. $2^{\mathrm{a}}$ ed. Campinas: edição da autora, 2000, p. 23-31.

Zwanziger, Iris. Die alte Truhe. $2^{\mathrm{a}}$ ed. Campinas: edição da autora, 2000, p. 31-34.

Zwanziger, Iris (Siri, Hilda). "Kleinigkeiten IV”. Zwanziger, Iris. Die alte Truhe. $2^{\mathrm{a}}$ ed. Campinas: edição da autora, 2000, p. 141-143.

Zwanziger, Iris (Siri, Hilda). "Du kannst ja heimkehren”. Zwanziger, Iris. Die alte Truhe. $2^{\mathrm{a}}$ ed. Campinas: edição da autora, 2000, p. 106. 
Zwanziger, Iris (Siri, Hilda). Die Parade. Die alte Truhe. $2^{\mathrm{a}}$ ed. Campinas, edição da autora, 2000, p. 156-158.

Recebido em: 01/05/2021

Aceito em: 14/07/2021

Publicado em setembro de 2021

Celeste Ribeiro de Sousa. E-mail: celeste@usp.br. ORCID: http://orcid. org/0000-0001-6044-8921. 